\title{
AC 2009-1171: A REMOTE LABORATORY FOR COLLABORATIVE EXPERIMENTS
}

\section{Jan Machotka, University of South Australia}

Jan Machotka is an electrical engineering graduate of the Czech Technical University in Prague. He spent more than 10 years working as a professional consultant in industry in Czechoslovakia and abroad. He started his academic career 20 years ago at the South Australian Institute of Technology. He is currently a Programme Director for undergraduate, postgraduate and transnational students at the University of South Australia, Adelaide, Australia. He is also responsible for final year students' projects for four engineering streams in the School of Electrical and Information Engineering. In recognition of his academic efforts, he has received highest University's and national awards. He is a Chartered Professional Engineer of Engineers Australia. His major research interests are in computer-aided methods in circuits and systems analysis, e-education, innovations in education, and remote laboratories and experiments. He is a project leader of one of the most successful innovative and learning projects - the remote laboratory NetLab, which has gained international recognition. He has published more than 60 publications, mostly in the field of engineering education.

\section{Zorica Nedic, University of South Australia}

Zorica Nedic received her BE degree in electrical engineering, specialising in electronics, in 1984 from the University of Belgrade, Serbia. She obtained her ME in electrical engineering in 1997 from the University of South Australia (UniSA), Adelaide, Australia. She worked for six years as a research and design engineer at the Institute Mihajilo Pupin in Belgrade, Serbia before migrating to Australia in 1991. Currently she holds a senior lecturer position in the School of Electrical and Information Engineering at UniSA. Her research interests include engineering education, remote laboratories and modelling biological vision.

\section{Andrew Nafalski, University of South Australia}

Andrew Nafalski's career spans several decades in academic and research institutions in Poland, Austria, the UK, Germany, France, Japan and Australia. He holds BEng(Hons), GradDipEd, MEng, PhD and DSc degrees. He is Chartered Professional Engineer and Fellow of the Institution of Engineers, Australia, Fellow of the Institution of Engineering and Technology (UK), Senior Member of the Institute of Electrical and Electronic Engineers (USA) and Honorary Member of the Golden Key International Honour Society. He is currently a Professor of Electrical Engineering at the University of South Australia in Adelaide and Professor of Information Technology and Computer Science at Lublin University of Technology, Lublin, Poland. His major research interests are related to electromagnetics, magnetic materials and measurements, engineering informatics as well as innovative methods in engineering education. His teaching areas cover analysis and design of electrical circuits and devices, electromagnetic compatibility and information technology. He has published over 300 scholarly works in the above fields. He has received numerous national and international awards for excellence in research, teaching, engineering education and community service.

\section{Ozdemir Gol, University of South Australia}

Özdemir Göl has had extensive experience as an engineering educator in addition to his substantial industrial experience. His academic career has included teaching and research in electrical engineering at universities in Turkey, Australia, France, Switzerland, Greece, Belgium and Finland. He holds the holder of MESc, ME and PhD degrees, all in electrical engineering. His research interests have been focused on electrical machines and drives, and include modelling and simulation of electrical machines using numerical methods and the application of mathematical techniques to design optimisation of electromagnetic devices. He is particularly interested in the design and development of novel electromechanical energy conversion devices, 
which integrate emerging active materials and non-conventional topologies. He has a strong interest in innovative approaches to engineering education and has published widely in this field. His teaching responsibilities have included courses in electrical machines, engineering design, renewable energy and virtual instrumentation. He has received national and international awards for excellence in research, teaching, engineering education and community service. He is the author and co-author of some 300 publications.

He is currently an Associate Professor and discipline head of Electrical Engineering at the University of South Australia, Adelaide, Australia. 


\title{
A Remote Laboratory for Collaborative Experiments
}

\begin{abstract}
Laboratory experiments are a fundamental and integral part of science and engineering education. In addition to reinforcing the theoretical concepts learnt, they also allow students to gain and develop vital skills associated with collaboration and communication. We have developed and implemented a remote laboratory at the University of South Australia (UniSA). One particular criterion in our case has been for the remote laboratory to facilitate student collaboration. It is currently used by both domestic and transnational students who collaborate in conducting joint experiments.
\end{abstract}

To evaluate the remote laboratory and its effectiveness in achieving the learning outcomes, domestic students in the Signals and System course were divided into 3 groups to conduct an identical experiment. The first group was asked to conduct the experiment in the actual laboratory. The second group was directed to conduct it using the remote laboratory. Students in the third group were given the choice to conduct experiment either in the actual laboratory or via the Internet in the remote laboratory or both. All students were asked to answer a short survey about their collaboration before, during and after the experiment. The student performance, activities and responses are discussed in this paper.

\section{Introduction}

Laboratory experiments are a fundamental and integral part of science and engineering education. In addition to reinforcing the theoretical concepts learnt, they allow students to gain and develop vital skills associated with collaboration and communication. However, despite this, real laboratory experiments have been increasingly complemented or replaced by simulation (onor off-line) and remote laboratories (RL). The primary reasons for this development must be seen in the reduced numbers of technical staff to provide laboratory supervision, the high cost of multiple sets of laboratory equipment, occupational health and safety regulations as well as time constraints. Comparative studies have been conducted on advantages and disadvantages of the three different types of laboratories, i.e. real, virtual and remote ${ }^{1,2}$. It has been investigated and documented that remote laboratories, if designed and implemented properly, secure similar, if not better, learning outcomes of the students - as compared with real laboratories ${ }^{3}$.

Remote laboratories allow experiments to be conducted on real laboratory equipment remotely via the Internet without time or location limitations. We have developed and implemented such a remote laboratory at the UniSA. This laboratory has been subject to continuing refinements and improvements via a number of sources, in particular through student user feedback. One particular criterion in our case has been for the remote laboratory to facilitate student collaboration. It is currently used by both domestic and transnational students, who collaborate in conducting joint experiments. Remote laboratories, which started their development about two decades ago, are currently seen as the humble beginning of the future global systems. They can be considered as a good structured and teaching environment for developing skills required for the efficient collaboration and communication on the local and global scale. In 2007 there were 
about 120 RLs at universities around the globe ${ }^{4}$, yet only a few were constructed in such way so as to allow involved participants to collaborate in real time, such as RLs developed as part of the MARVELL (Virtual Laboratory in Mechatronics: Access to Remote and Virtual e-Learning) project $^{5}$, DIESEL (Distance Internet - Based Embedded System Experimental Laboratory) project $^{6}$ and WebLab at MIT (Massachusetts Institute of Technology) ${ }^{7}$. In our paper we describe the remote laboratory NetLab, which has been developed at the UniSA and incorporated into curriculum of engineering courses. The laboratory enables students and visitors from remote locations to conduct experiments in a collaborative way. It is used with our onshore local students as well as with our offshore students in Singapore, Malaysia and Sri Lanka.

\section{Collaboration and cooperation}

Students' collaboration and cooperation skills are developed by conducting projects that involve a joint intellectual undertaking by the students or students and their teachers. Collaborative learning or cooperative learning are types of situated learning that include, group activities with particular emphasis on cooperation rather competition among students. These types require students to develop additional skills such as the ability to work effectively in groups. Cooperative learning is distinguished from collaborative learning. In cooperative learning teachers take most of responsibility for decisions about the subject matter and how the groups are to cooperate, while in collaborative non-competitive learning group activities, students are engaged in making decisions about what is learned and how ${ }^{8}$. Collaborative learning has been defined in a number ways, but it is generally understood to refer to small group learning, where the group members actively support the learning processes of one another ${ }^{9}$. The introduction of the Internet has contributed to the further development of cooperative learning environments online $^{10}$. The collaborative learning environments range from the small group learning confined to the classroom or laboratory to the advanced cyber space domain, where the computing and information technology have increasingly assumed a dominant importance ${ }^{11}$.

Collaborative work has always been anchored in engineering practice, as engineers seldom work in isolation. Great engineering projects must be created by a team of engineers and consequently collaborative learning is most suited and a natural part in preparing engineering students for the challenges that lie ahead. Furthermore, collaborative learning enables developers of teaching systems to work as a network. This is specifically relevant to on-line learning where developers can communicate and build knowledge into courses in a collaborative environment and information regarding a single subject can be brought together from different remote locations using specifically designed software systems.

Generally, student laboratory work involves the following steps and procedures:

- Student preparation for experiments

- Conducting experiments

- Analysis of results

- Submitting practical reports

- Assessment

- Evaluation and reflection

Collaboration among students can be encouraged during preparation, conduct and analysis of experiments, where students are asked to work in teams. This can be implemented for peer assessment, 
evaluation and reflection as well. Findings from our survey provide some information about student collaboration before, during and after the practical experiment.

\section{Remote laboratory}

A remote laboratory (RL) allows a real physical system set in a laboratory to be remotely controlled from a computer via the Internet using virtual instruments. The system also enables experimental data to be collected and transferred to the remote user for further analysis. The user then is able to view experimental results and analytical outcomes on a computer screen, watch them on the lecture theatre screen, or submit them in electronic form for assessment. The controlled instruments are seen on the computer screen with animated displays. A live view is available from the active web camera, which can be controlled remotely. The RL has its own dedicated server which is connected to the Internet allowing users to access the RL. On the other hand, the server communicates with a number of programmable laboratory instruments via the IEEE 488.2 standard interface, known as the General Purpose Interface Bus (GPIB). These instruments include a digital oscilloscope, a function generator and a digital multimeter. The current set-up of the RL is shown in Figure 1.

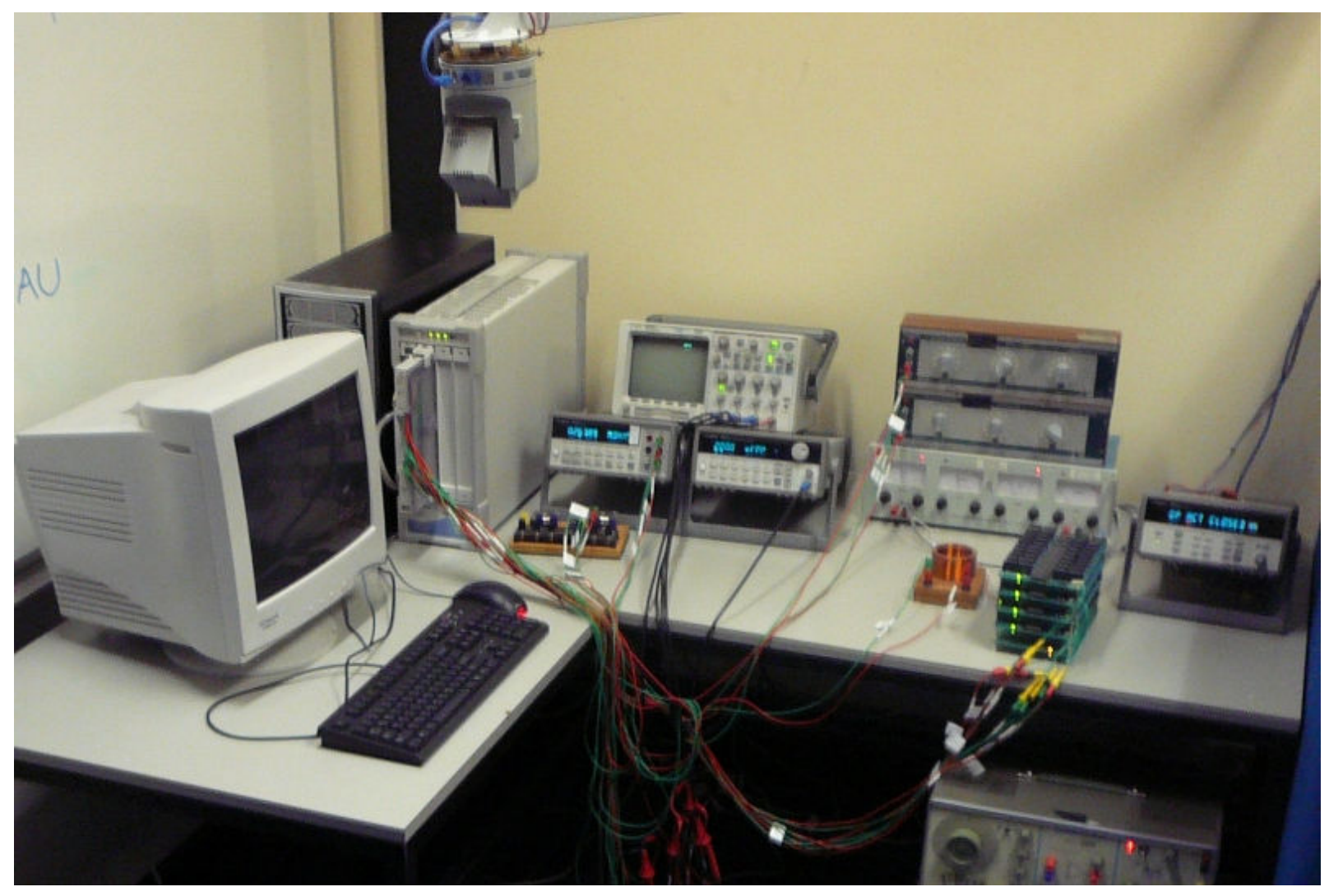

Figure 1. RL set-up in January 2009

All these instruments are also connected to a 16x16 programmable matrix relay switch which provides the user with an option to wire and configure various electrical circuits from available components and instruments. A special software, dubbed the Circuit Builder, has been developed for this purpose. The RL Graphical User Interface (GUI) is written in Java, therefore the Java Runtime Environment (JRE) must be installed to allow the RL application to run. The user can control the real instruments through the client 
software, consisting of the interactive GUI as shown in Figure 2. The GUI is the most distinctive part of the RL. From the beginning of its development it has been designed with the intention of giving students the feel of working in a real laboratory as much as possible. Students interact with instruments by pushing and turning buttons on realistically emulated images of the instrument control panels. The button responses are animated (they turn or light up, etc) in the same way as on the real instrument to give users immediate feedback to their action. The only difference is that students use the mouse instead of their fingers to control instruments.

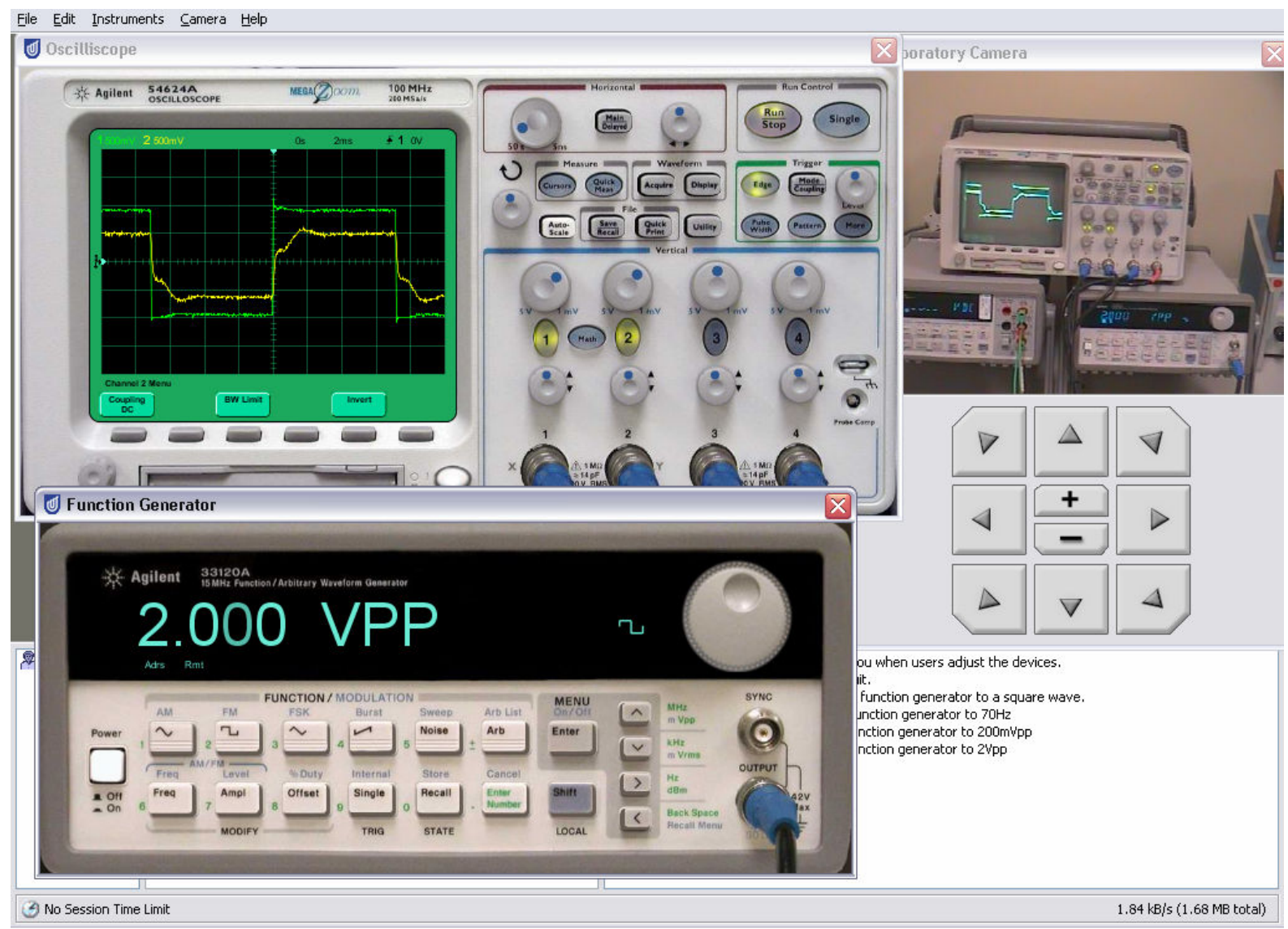

Figure 2. The NetLab user GUI

The users' commands are then sent to the NetLab server and processed by the server software. The RL server was originally written in LabView as were other other RL servers ${ }^{12}$. Currently the NetLab server uses an implementation of the Virtual Instrumentation Software Architecture (VISA) Application Programming Interface (API) to direct the commands to the appropriate programmable instrument. The VISA API allows software to communicate with a variety of hardware devices using connections from the same software interface. The GPIB port is used to retrieve the relevant data from the instruments and passed on to all connected users. The data, acquired by the oscilloscope, can then be exported to a file for use with relevant software such as MATLAB for further processing and analysis. Components that are currently available are resistors, capacitors, inductors and transformers. In addition, programmable variable resistors, inductors and capacitors have been developed and interfaced into the system. Additional components can be easily added to or removed from the system at any time. The RL also includes a camera which has its own web server and is fully controllable by the user. The camera controls include pan, tilt and zoom functions. The video feed from the camera is not part of any experiment and 
can be switched off to save on the bandwidth. However, it is an important part of the system because it provides distant users with tele-presence in the laboratory ${ }^{4}$.

\section{RL booking system}

Both client and server software housed on the RL server are written in Java. The system requires a new user to create an account and then to book a session. As a multiuser collaborative environment, the RL allows more than one user to have full control of the system at the same time. However, the number of concurrent users is now limited to three in order to prevent chaos in the laboratory! The flexibility of the system allows each student to book 1, 2 or 3 sessions, so that the students can work in groups of 3, 2 or alone. To prevent excessive booking, the course coordiantor (administrator) can set a limit on a number of hours per week that each student can book. When the cursor is positioned over a booked slot, the user name and location (except Australia as a default) is displayed. This provides students with an option to choose a laboratory partner from another country. An unlimited number of users with administrative privileges can access and control the system at any time without booking even if three other users are logged on.

Students can log on and access NetLab at their booked time. The booking system can become quite busy as illustrated by Figure 3, when students from elsewhere try to catch up with an assignment deadline.

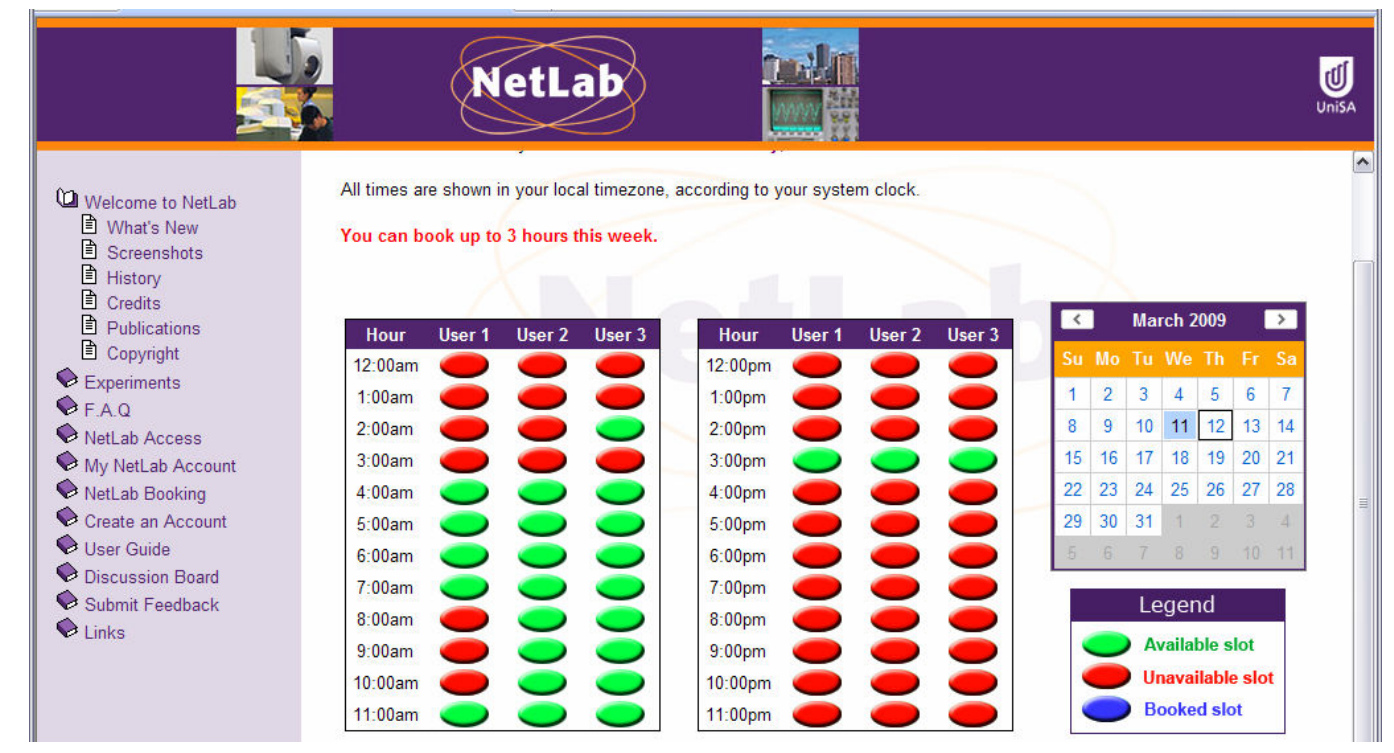

Figure 3. The booking system becomes busy when reports are due.

\section{Practical experiment}

The objective of this experiment is to create two different models of an inductively coupled third order system as shown in Figure $4 a$. and $4 b$.

The experiment is part of a whole collaborative project. Students are required to prepare, conduct and analyse the remote experiment and then use the results to design two different models of the system under investigation and to conduct simulations. They have to compare the obtained responses and discuss possible discrepancies. All activities are conducted in a collaborative way, 
which requires students to work as a team. In this project, measured and calculated results are prerequisites for the next steps of the experiment. This leads to better understanding of the whole process and thus students learning outcomes are enhanced.

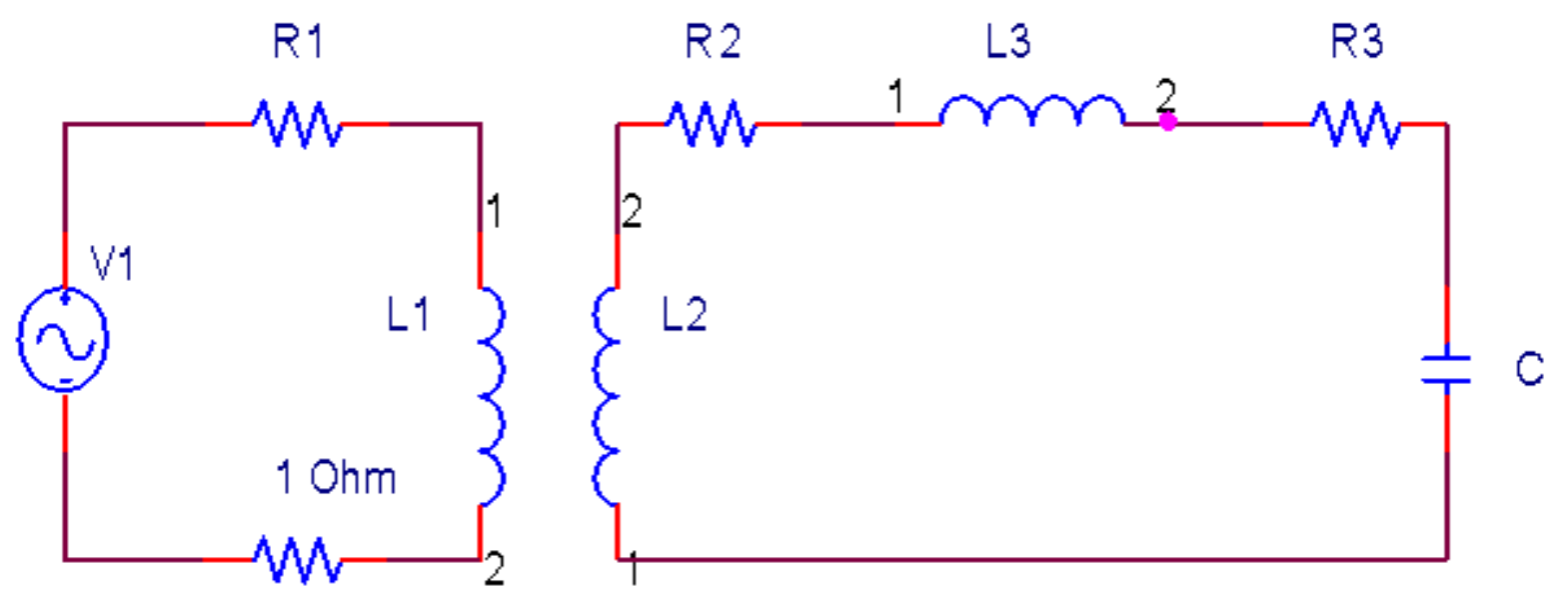

Figure 4a. Schematics of an inductively coupled system.

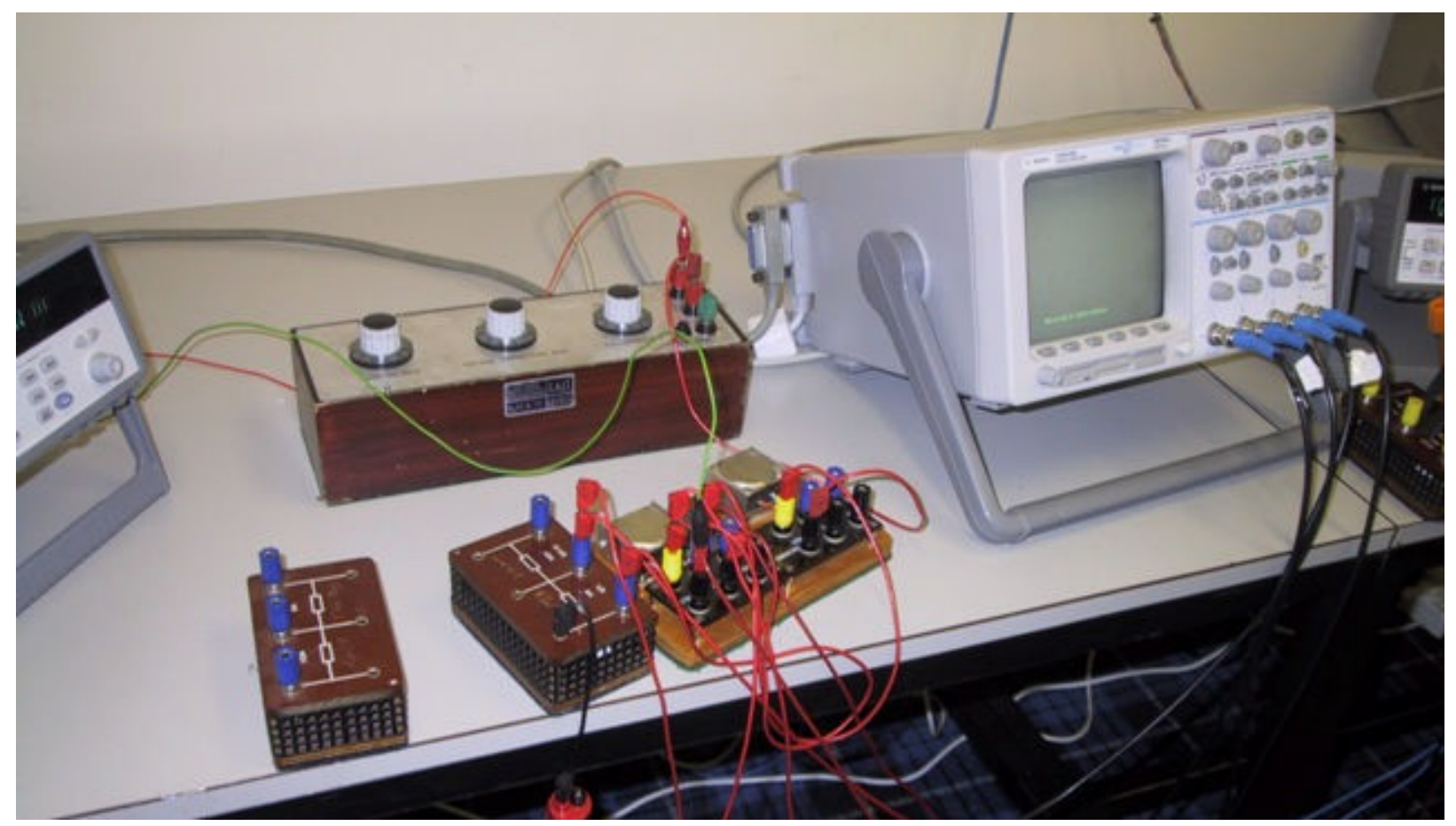

Figure 4b. The actual set-up in the RL

Using the NetLab, students must at first connect real components using the Circuit Builder as shown in Figure 5. 


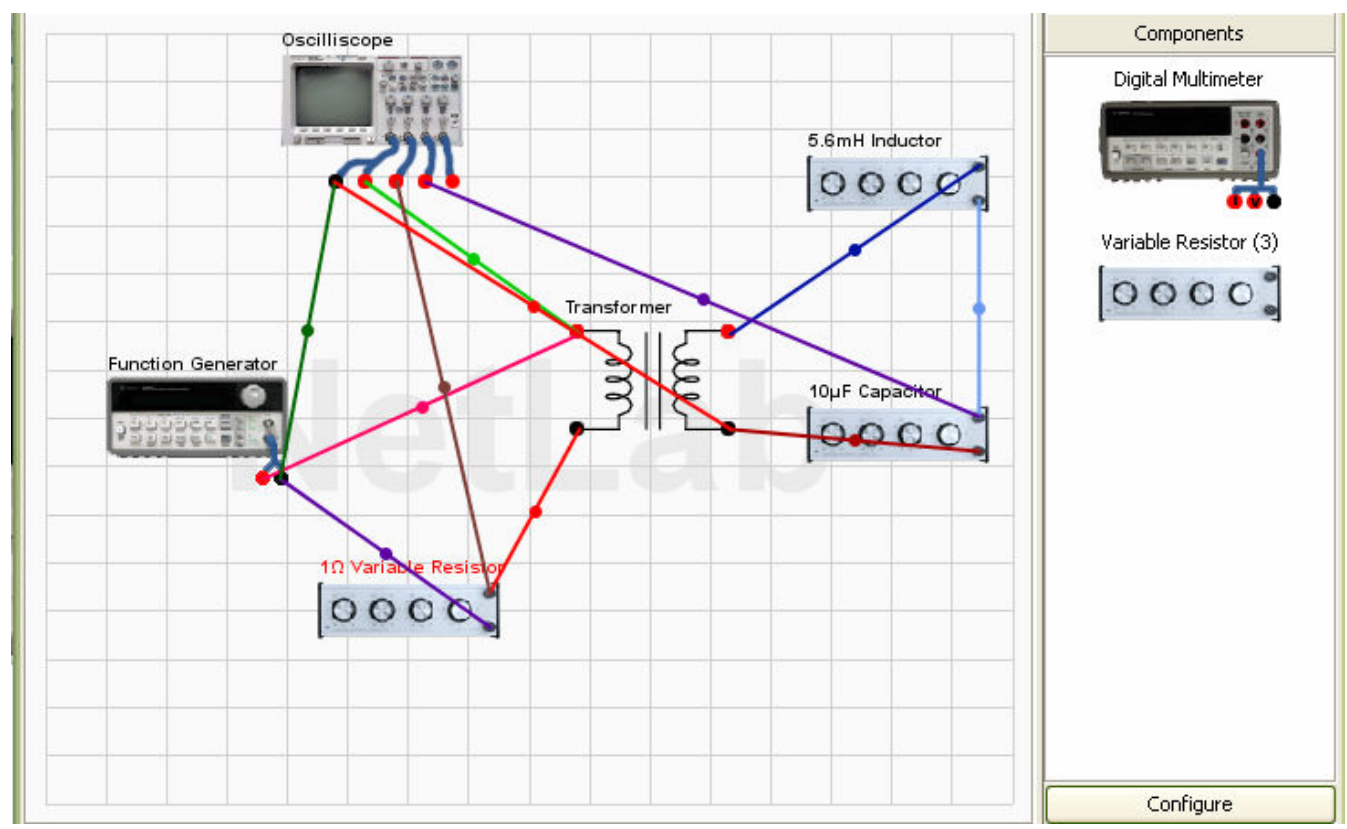

Figure 5. The Circuit Builder connection for the experiment.

The next step is to propose proper tests to measure and/or calculate values of all components of the system. This is one of the most demanding tasks, as no detailed instructions are given to the students. They have to collaborate to find, agree on and understand the possible tests, evaluation of tests and calculation of required values. Conducting the agreed experiments follows. The last experiment is required to obtain the system step input responses. All stages require real collaboration, as they require control of the function generator and the digital storage CRO. During the experiment, the users in the RL communicate via the chat window to achieve a successful outcome. After obtaining and saving all required data, the experiment is over. The next stage is to evaluate the results and to obtain parameters, which can be used to create two models of the system. The first model is the schematics for the PSpice (Simulation Program with Integrated Circuit Emphasis) simulation as shown in Figure 6.

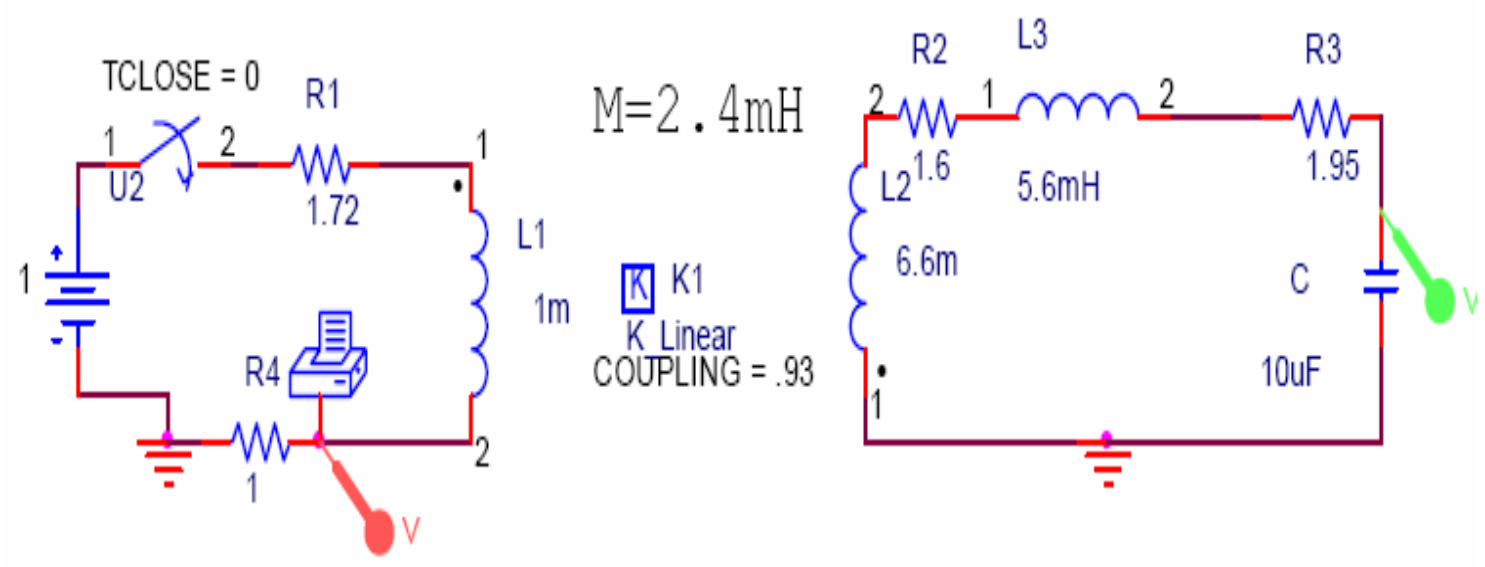

Figure 6. PSpice schematics for the simulation. 
The second model is based on the calculated system transfer function shown below and used for the MATLAB simulation.

$$
H(s)=\frac{s^{2}\left(L_{3}+L_{2}\right)+s\left(R_{2}+R_{3}\right)+\frac{1}{C}}{s^{3}\left(L_{1} L_{3}+L_{1} L_{2}+L_{3}+L_{2}-M^{2}\right)+s^{2}\left(R_{1} L_{3}+R_{1} L_{2}+R_{2} L_{1}\right)+s\left(R_{1} R_{2}+R_{1} R_{3}+\frac{L_{1}}{C}+L_{1} R_{3}+R_{2}+R_{3}\right)+\frac{R_{1}}{C}+\frac{1}{C}}
$$

This phase of the whole exercise can be done in different ways. Users can split tasks and later compile their parts to obtain the overall results or they can work simultaneously on the same tasks and later compare their results. This requires effective communication and collaboration. Simulation system responses are compared with the real responses from the remote experiment. If there are discrepancies - and usually there are - the collaborative work resumes. The discussion about possible errors or mistakes should reveal suggestions where the mistakes and errors were made and found. If necessary and possible, the experiment or its parts are repeated.

Final successful graphical comparison of the real response and simulation responses are shown in Figure 7. As can be seen, if both simulations are executed in a proper way and are based on correctly measured and calculated parameters, the responses should be nearly identical. They are slightly different in the case of the measured responses acquired via the RL measurements.

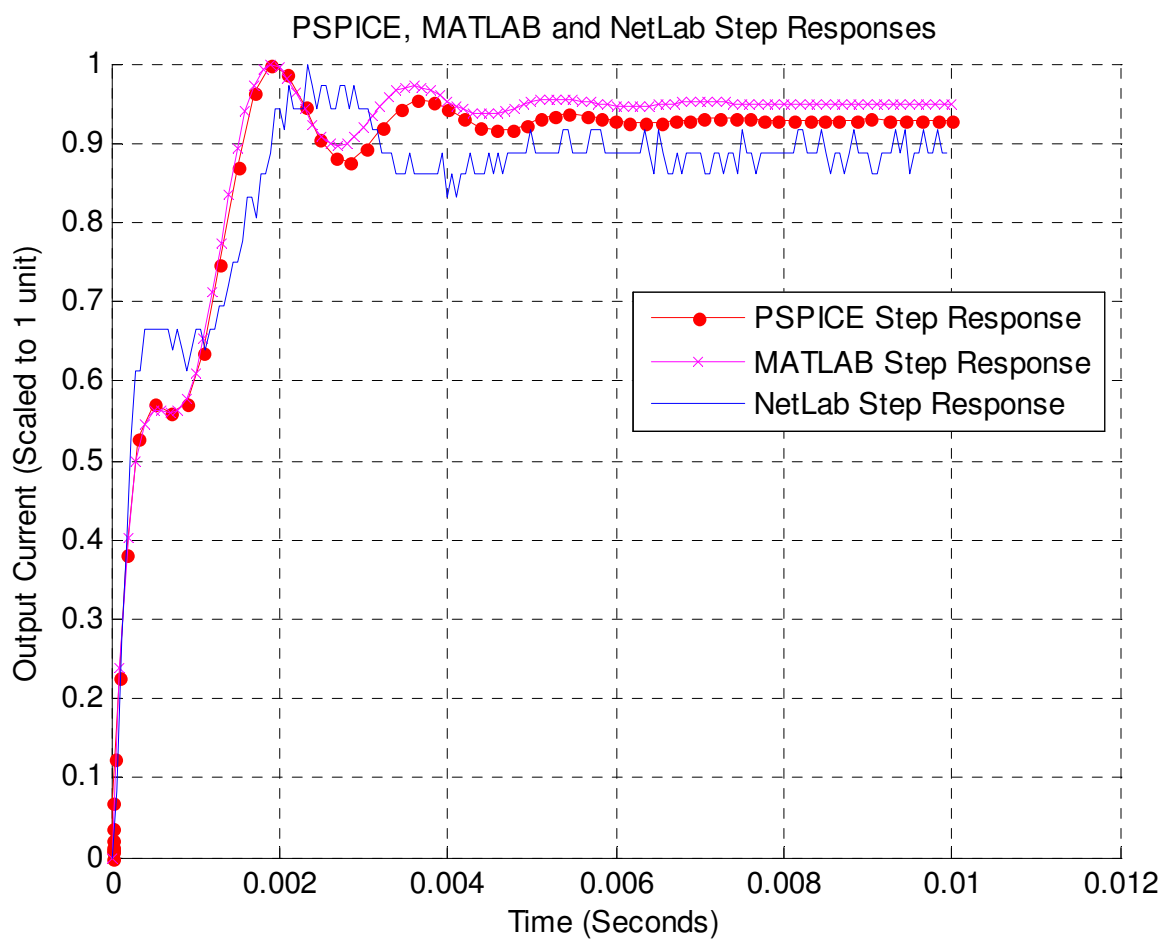

Figure 7. Graphical comparison of responses 
An advantage of this experiment from the supervisor's view is the assessment of the whole project by just comparing the responses obtained. This can also be performed by students, as they can see if they did or did not obtain the required matching responses from the real experiment and two simulations. In the case of RL, an immediate back to back repeat of the whole experiment can be performed, wholly or partly, which is nearly impossible in the real laboratory, where a second attempt is usually not allowed.

Some "not the best" results are shown in Figures 8.

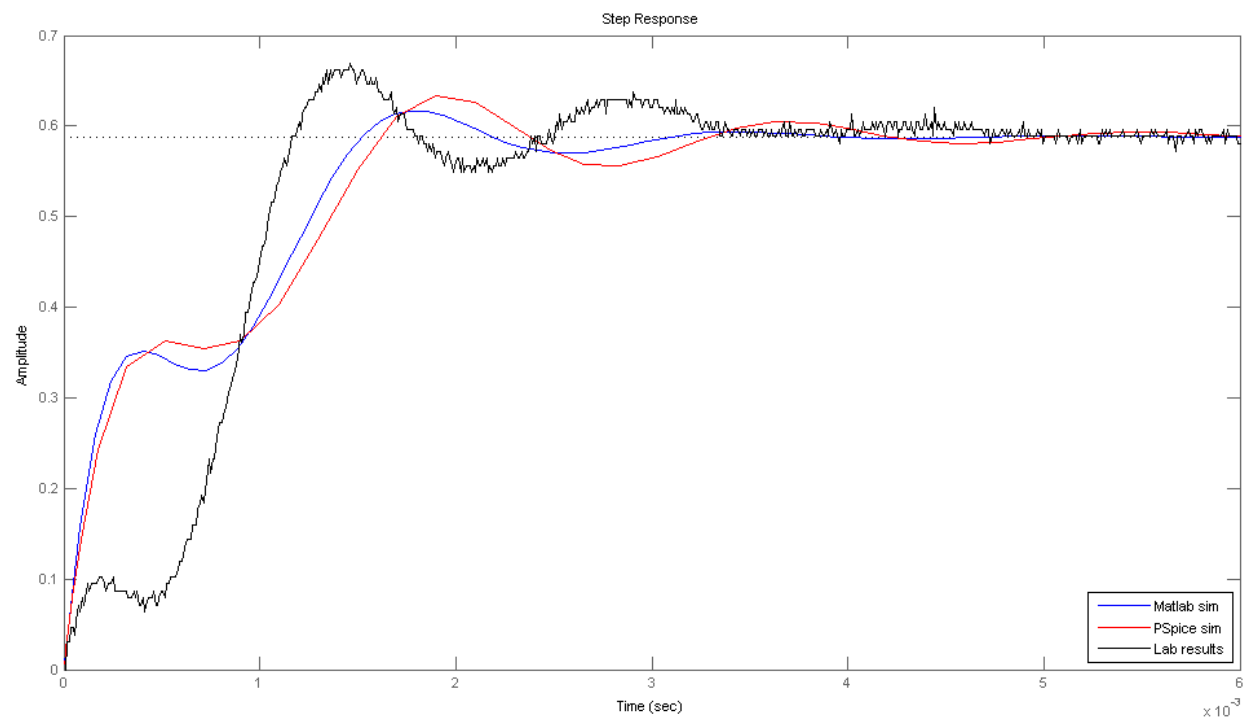

Figure 8. Graphical comparison with incorrect graphs.

\section{Student experiments in different modes}

The described experiment has been practiced and conducted at our school for last 10 years. In its original form it was conducted by groups of up to 3 students, who were supervised by the instructor. After incorporation of the remote laboratory into curriculum this experiment has been available online during the last 5 years. As our remote laboratory incorporates and promotes a collaborative design aspect, effective teamwork is essential for students in a similar way as it would be in the real laboratory. Each experiment has the traditional pre and post laboratory phases or segments, where initially students have to do the preparation for the experiment, and subsequently analyse the results and compile a report after the experiment. These two segments should be identical for both real and remote experiments. To investigate and compare both the student collaboration and learning outcomes during the pre and post experiment activities for the different mode of experiments (real and remote), the following course of action has been adopted. Students are divided into 3 groups to conduct an identical experiment. The first group is asked to conduct the experiment in the actual laboratory. The second group is directed to conduct it using the remote laboratory. Students in the third group are given the choice to conduct the experiment either in the actual laboratory or via the Internet in the remote laboratory or both. After the experiment students are asked to answer a short survey. During the first part of the semester, students in the course Signals and Systems conduct different experiments in the laboratory and the computer pool and are allocated to 8 different time slots during the week with 
different number of students in each timeslot. To make it as realistic as possible, so students can work with the same partners, the original time slot groups were kept for survey, where 2 groups each were allocated for the actual and remote experiments and four groups were allocated for the remote and/or actual experiments. As seen in Table 1, there were 5 groups with a total of 15 students in Actual Experiment (A). 7 groups with a total of 12students took part in the Remote Experiment (R) as shown in Table 2. A further 16 groups with a total of 33 students exercised their option of choosing between actual or remote experiment or doing both. Tables $4 \mathrm{a}$ and $4 \mathrm{~b}$ show student groups divided according to their choice of experiment. All student reports were assessed by the same instructor who also supervised the students during the actual experiments and marks (including the average marks) are shown in tables below.

Table 1 - Actual experiment

\begin{tabular}{|c|c|c|c|c|}
\hline Group A & & Students & Marks & \\
\hline 1 & A & 3 & 9.5 & \\
\hline 2 & A & 3 & 10 & \\
\hline 3 & A & 3 & 9.5 & \\
\hline 4 & A & 3 & 9.5 & \\
\hline 5 & A & 3 & 10 & \\
\hline & $\begin{array}{c}\text { Total } \\
\text { number of } \\
\text { students }\end{array}$ & 15 & $\begin{array}{c}\text { Average } \\
\text { mark }\end{array}$ & 9.7 \\
\hline
\end{tabular}

Table 2 - Remote experiment

\begin{tabular}{|c|c|c|c|c|}
\hline Group & & Students & Marks & \\
\hline 1 & $\mathrm{R}$ & 3 & 10 & \\
\hline 2 & $\mathrm{R}$ & 2 & 10 & \\
\hline 3 & $\mathrm{R}$ & 3 & 10 & \\
\hline 4 & $\mathrm{R}$ & 2 & 8 & \\
\hline 5 & $\mathrm{R}$ & 2 & 10 & \\
\hline 6 & $\mathrm{R}$ & 2 & 10 & \\
\hline 7 & $\mathrm{R}$ & 3 & 10 & \\
\hline & $\begin{array}{c}\text { Total } \\
\text { number of } \\
\text { students }\end{array}$ & 12 & $\begin{array}{c}\text { Average } \\
\text { mark }\end{array}$ & 9.666 \\
\hline
\end{tabular}


Table 3 - Actual and/or remote experiment

\begin{tabular}{|c|c|c|c|l|}
\hline Group & & Students & Marks & \\
\hline 1 & $\mathrm{~N}$ & 1 & 10 & \\
\hline 2 & $\mathrm{~A}$ & 2 & 7.5 & \\
\hline 3 & $\mathrm{~A}$ & 3 & 10 & \\
\hline 4 & $\mathrm{~A}$ & 2 & 9 & \\
\hline 5 & $\mathrm{~A}$ & 2 & 9.5 & \\
\hline 6 & $\mathrm{~A}$ & 2 & 10 & \\
\hline 7 & $\mathrm{R}$ & 2 & 10 & \\
\hline 8 & $\mathrm{~A}$ & 2 & 10 & \\
\hline 9 & $\mathrm{~A}$ & 2 & 7.5 & \\
\hline 10 & $\mathrm{~A}$ & 2 & 10 & \\
\hline 11 & $\mathrm{~A}$ & 3 & 6 & \\
\hline 12 & $\mathrm{~A}$ & 1 & 9.5 & \\
\hline 13 & $\mathrm{R}$ & 2 & 10 & \\
\hline 14 & $\mathrm{~A}$ & 3 & 10 & \\
\hline 15 & $\mathrm{~A}$ & 3 & 10 & \\
\hline 16 & $\mathrm{R}$ & 1 & 10 & \\
\hline & $\begin{array}{c}\text { Total } \\
\text { number of } \\
\text { students }\end{array}$ & 33 & Average & \multirow{2}{*}{9.227} \\
\hline
\end{tabular}

Table $4 \mathrm{a}$ - Actual experiment

\begin{tabular}{|c|c|c|c|c|}
\hline Group & & Students & Marks & \\
\hline 1 & $A$ & 2 & 7.5 & \\
\hline 2 & A & 3 & 10 & \\
\hline 3 & A & 2 & 9 & \\
\hline 4 & A & 2 & 9.5 & \\
\hline 5 & $A$ & 2 & 10 & \\
\hline 6 & A & 2 & 10 & \\
\hline 7 & A & 2 & 7.5 & \\
\hline 8 & $A$ & 2 & 10 & \\
\hline 9 & $A$ & 3 & 6 & \\
\hline 10 & A & 1 & 9.5 & \\
\hline 11 & A & 3 & 10 & \\
\hline \multirow[t]{2}{*}{12} & $A$ & 3 & 10 & \\
\hline & $\begin{array}{c}\text { Total } \\
\text { number of } \\
\text { students }\end{array}$ & 27 & $\begin{array}{c}\text { Average } \\
\text { mark }\end{array}$ & 8.732 \\
\hline
\end{tabular}

$$
\begin{aligned}
& \text { ரै } \\
& \stackrel{0}{\mathbb{D}} \\
& \vec{D} \\
& \overrightarrow{0} \\
& \stackrel{0}{\omega} \\
& \vec{\omega}
\end{aligned}
$$


Table $4 \mathrm{~b}-$ Remote experiment

\begin{tabular}{|c|c|c|c|c|}
\hline Group & Students & Marks & \\
\hline 1 & $\mathrm{R}$ & 1 & 10 & \\
\hline 2 & $\mathrm{R}$ & 2 & 10 & \\
\hline 3 & $\mathrm{R}$ & 2 & 10 & \\
\hline 4 & $\mathrm{R}$ & 1 & 10 & \\
\hline & $\begin{array}{c}\text { Total } \\
\text { number of } \\
\text { students }\end{array}$ & 6 & $\begin{array}{c}\text { Average } \\
\text { mark }\end{array}$ & 10 \\
\hline
\end{tabular}

Several observations are made from the tables above:

All students achieved relatively high marks for this experiment and all the reports were of high quality.

The best average mark was achieved by students who decided to conduct the remote experiment if given the choice between the two modes.

The worst average mark was achieved by students who decided to conduct the actual experiment if given the choice between the two modes. It is noteworthy that the average mark of this group is reduced to a low mark of 6 . Given the fact that this mark is somewhat unusual in the context of all the other results it could be argued that it is not statistically significant and could have been disregarded.

The students allocated to remote or real experiments achieved about the same average mark.

None of the students opted to conduct both experiments. This could be due to the scheduling of the experiment, as it took place at the end of the first semester when final reports and assignments were due for other courses.

Table 3 indicates that given the choice, students' preferences still lie with the real laboratory experiment over that of the remote experiment. However, it is interesting to note that that those who chose to perform the remote experiment achieved higher marks. Moreover, all students who had the choice between the two modes and conducted the remote experiment obtained the highest possible mark.

\section{Student survey on collaboration}

After having conducted the experiments, students were asked to answer a few questions about their activities before, during and after the experiment. The questionnaire was to be submitted with their final report including any general comments. There were 4 different sets of questions.

The first set of questions was intended for all students:

Have you worked alone? 
If not, how many students were in your group?

How much time have you spent on your preparation?

Have you done your preparation for the practical by yourself only or with partners?

If you have done your preparation as a group, how have you collaborated on it? Briefly describe:

During the experiment did you work together with other students?

How much time did you spend on the experiment (step input only)?

How much time did you spend on the bonus part of the experiment (voltage across the capacitance)?

How much time did you spend preparing your report?

If you have done your report as a group, how did you collaborate on it? Briefly describe:

The second set of questions was intended only for students conducting the experiment in the actual laboratory (Group A). The third set of questions was intended only for students conducting the experiment remotely (Group B) and the last set of questions was intended for students who had a choice of conducting the experiment in the real laboratory or the remote laboratory or both. The complete analysis of all student responses is beyond the scope of this paper, thus only the questions and their answers as well as students comments from the first set are included here.

Response to student questionnaires was not compulsory. Yet about $80 \%$ of students submitted a response together with their reports. Surprisingly, the lowest return - only about 30\% - occurred in group B - remote experiment only. All responses were submitted electronically.

\section{Preparation for the experiment}

The submitted questionnaires were a comparatively large sample of the whole number of students (60 students). About 60\% conducted their preparation together in the group and 30\% made their own preparation, even when working on the experiment as a group. Obviously, students working alone performed their own preparation. The rest of the students admitted they had not done any preparation whatsoever. The time spent on preparation ranged from 30 minutes to 10 hours. Average time spent on preparation was 2 hours.

\section{Analysis of results and the report writing}

As students were directed to submit group reports, only those performing their experiment by themselves performed this phase individually. The remaining students working in groups collaborated on the analysis of results and reports.

Surprisingly the collaboration during the analysis stage was done in a different mode compared with the collaboration during the preparation stage. During the analysis stage students were working together at the same time and the same place, however, during the preparation stage the collaboration took the form of discussion.

The majority of students (90\%) divided their tasks and worked separately for the analysis and drafting up the reports. This was done in two separate ways. Firstly, each member of the team would be allocated a task and these would be later compiled together. The second, less common, method was to split tasks in a sequential way, so when the first part is finished, it is passed to the 
second student and then onto the third student and so on. Sometimes this was done via the Internet in electronic form or via telephone.

The time spent ranged from 2 hours to up to 6 hours per students. As students from the same group usually worked at different times, analysis and report writing was spread over several days.

\section{Conclusion}

Based on observations some general conclusions can be drawn.

There appears to be no link between the level of results which can be achieved and the mode of experimental method performed. That is to say, high marks can be achieved by students regardless of whether they perform the same experiment via remote or traditional means. This would tend to suggest that the same level of learning exists within each method.

The collaboration of students during the preparation stage and analysis/report writing stage seems to be the same regardless whether the experiments are conducted remotely or in the real laboratory. The only difference between those stages is that usually the preparation is done in the synchronous mode whilst the final stage is done in asynchronous mode with sometime the newest information technologies involved.

The most popular method for the collaborative learning group to produce a final report is for each member of the team to be allocated a clear objective for completion and then for these objectives to be pieced together to form the final report. This would seem more time efficient than the alternative of passing on the report to each member to complete their allocated portion sequentially. It would be appropriate to suggest and outline this method of report preparation to students working in a collaborative team environment in the future.

A possible follow up to the first part of this study would be to have students perform both modes of the experiment. As discussed before, this study lacked such results as none of the student chose this option due to the time of the experiments. Therefore, such a follow up study should be scheduled at the beginning or mid semester. The students' comments on the comparison of the two modes could lead to further related discussion.

\section{Bibliography}

1. Z. Nedic, J. Machotka, and A. Nafalski, "Remote laboratories versus virtual and real laboratories," in $33^{\text {rd }}$ ASEE/IEEE Frontiers in Education Conference, Boulder, Colorado, USA, 2003, pp. T3E1-T3E6.

2. J. E. Corter, J. V. Nickerson, S. K. Esche, and C. Chassapis, "Remote versus hands-on labs: a comparative study," in 34th ASEE/IEEE Frontiers in Education Conference, Savannah, GA, USA, 2004, pp. F1G17-F1G21.

3. D. S. Sicker, T. Lookabaugh, J. Santos, and F. Barnes, "Assessing the Effectiveness of Remote Networking Laboratories," in 35th ASEE/IEEE Frontiers in Education Conference, Indianapolis, 2005, pp. S3F-7. 
4. S. Gröber, M. Vetter, B. Eckert, and H.-J. Jodl, "Experimenting from a Distance Remotely Controlled Laboratory (RCL)," To appear in European Journal of Physics, 2007.

5. D. Müller and J. M. Ferreira, "Online labs and the MARVEL experience," International Journal of Online Engineering, vol. 1, 2005.

6. M. J. Callaghan, J. Harkin, T. M. McColgan, T. M. McGinnity, and L. P. Maquire, "Client-server architecture for collaborative remote experimentation," Journal of Computer Assisted Learning, vol. 30, 2007.

7. J. A. d. Alamo, V. Chang, L. Brooks, C. McLean, J. Hardison, G. Mishuris, and L. Hui, "MIT Microelectronics WebLab," in LAB on the WEB, Running Real Electronics Experiments via the Internet, T. A. Fjeldly and M. S. Shur, Eds. New York, NY: John Wiley \& Sons, 2003, pp. 49 - 87.

8. C.D.Maddux, D.LaMont, and D.Johnson, The Web in Higher Education: Assessing The Impactand Fulfilling The Potentia. New York: The Haworth Press, Inc., 2001.

9. $\quad$ Ö.Göl and A.Nafalski, "Collaborative Learning in Engineering Education," in UICEE 10th Annual Conference On Engineering Education, Bangkok, Thailand, 2007.

10. T.S.Roberts, Online Collaborative Learning: Theory and Practice. London: Information Science Publishing, 2004.

11. M.A.Purvis, B.T.R.Savarimuthu, and M.K.Purvis, "Architecture for Active and Collaborative Learning in a Distributed Classroom Environment." vol. 4: Advanced Technology for Learning, 2006, pp. 225-232.

12. M. Hla and S. Lakeou, "Remote Monitoring and Control of GPIB-based Electronic Experiment," in 2004 American Society for Engineering Education Annual Conference \& Exposition, 2004, p. Session:1532. 